\title{
Familial Mediterranean Fever (FMF) and renal disease: first report on 29 Sicilian patients
}

\author{
A Vitale*, F La Torre, G Conti, C Fede, R Chimenz and G Calcagno
}

Address: Department of Pediatrics, Pediatric Rheumatology, Messina, Italy

* Corresponding author

from $15^{\text {th }}$ Paediatric Rheumatology European Society (PreS) Congress

London, UK. 14-17 September 2008

Published: 15 September 2008

Pediatric Rheumatology 2008, 6(Suppl I):PI76 doi:I0.II86/I546-0096-6-SI-PI76

This abstract is available from: http://www.ped-rheum.com/content/6/SI/PI76

(C) 2008 Vitale et al; licensee BioMed Central Ltd.

\section{Background}

Familial Mediterranean Fever (FMF) is characterized by recurrent attacks of fever and serositis. Amyloidosis is its most crucial complication. Methods: Between 2002 and 2007, 29 patients (11 girls, 18 boys) median age 316 months in whom FMF was diagnosed and with a followup period of at least six months were included in the study.

The mean age of the patients at the time of the onset was 110 +- 106 months. Genetic mutations more frequently detected were M680I (12/29) and M694V (8/29). Age of starting colchicine was $267+-180$ months. The patients were followed at 6 month intervals; at each visit, daily urinary protein excretions were calculated.

\section{Results}

5 patients showed a proteinuric stage without fever attacks, but two of them were non compliant with the treatment.

There were no significant differences (age at onset, initial dose of colchicine and serum amyloid A levels) in the two groups. The FMF patients with elevated proteinuria showed a short time between the age of onset and the starting of colchicine than ones with normal proteinuria. Two patients with pathological proteinuria did not have MEFV gene mutations. After the increase of colchicine, there was the complete resolution of proteinuria in all patients.

\section{Conclusion}

Colchicine is an effective medication in the prevention and treatment of amyloidosis; In contrast to other reported studies, there was no correlation between amyloidosis and M694V homozygosity in this cohort. Ten patients of our population who received a delayed diagnosis (median age of diagnosis 40 years) don't show renal damage. 